\title{
The impact of Mir-9 regulation in normal and malignant hematopoiesis
}

\author{
Abbas Khosravi, ${ }^{1}$ Shaban Alizadeh, ${ }^{2}$ Arsalan Jalili, ${ }^{3}$ Reza Shirzad, ${ }^{4}$ Najmaldin Saki ${ }^{5}$ \\ ${ }^{1}$ Transfusion Research Center, High Institute for Research and Education in Transfusion Medi-cine, Tehran; \\ ${ }^{2}$ Hematology Department, Allied Medical School, Tehran University of Medical Sciences, Tehran; ${ }^{3}$ Department of Stem \\ Cells and Developmental Biology at Cell Science Re-search Center, Royan Institute for Stem Cell Biology and \\ Technology, ACECR, Tehran; ${ }^{4}$ WHO Collaborating Center for Reference and Research on Rabies, Pasteur Institute of \\ Iran, Tehran; ${ }^{5}$ Thalassemia \& Hemoglobinopathy Research Center, Research Institute of Health, Ahvaz Jun-dishapur \\ University of Medical Sciences, Ahvaz, Iran
}

\begin{abstract}
MicroRNA-9 (MiR-9) dysregulation has been observed in various cancers. Recently, MiR-9 is considered to have a part in hematopoiesis and hematologic malignancies. However, its importance in blood neoplasms is not yet well defined. Thus, this study was conducted in order to assess the significance of MiR-9 role in the development of hematologic neoplasia, prognosis, and treatment approaches. We have shown that a large number of MiR-9 targets (such as FOXOs, SIRT1, CCND1, ID2, CCNG1, Ets, and NFkB) play essential roles in leukemogenesis and that it is overexpressed in different leukemias. Our findings indicated MiR-9 downregulation in a majority of leukemias. However, its overexpression was reported in patients with dysregulated MiR-9 controlling factors (such as MLLr). Additionally, prognostic value of MiR-9 has been reported in some types of leukemia. This study generally emphasizes on the critical role of MiR-9 in hematologic malignancies as a prognostic factor and a therapeutic target.
\end{abstract}

\footnotetext{
Correspondence: Najmaldin Saki, Thalassemia \& Hemoglobinopathy Research Center, re-search institute of health, Ahvaz Jundishapur University of Medical Sciences, Ahvaz, Iran. Tel.: +98.6113738317 Fax:+98.6113738330. E-mail: najmaldinsaki@gmail.com
}

Key words: MiR-9; leukemia; tumor suppressor; oncogene.

Acknowledgements: we wish to thank all our colleagues in High Institute for Research and Education in Transfusion Medicine, Tehran, Iran.

Contributions: NS, conceived the manuscript and revised it; AK, SA, $\mathrm{AJ}$, wrote the manu-script and prepared the tables. RS, AK, designed the figures and performed the bioinformatic analysis.

Conflict of interest: the authors declare that they have no conflict of interest.

Received for publication: 25 December 2017.

Revision received: 28 February 2018

Accepted for publication: 1 March 2018.

This work is licensed under a Creative Commons Attribution NonCommercial 4.0 License (CC BY-NC 4.0).

CCopyright A. Khosravi et al., 2018

Licensee PAGEPress, Italy

Oncology Reviews 2018; 12:348

doi:10.4081/oncol.2018.348

\section{Introduction}

Leukemia is caused by the uncontrolled proliferation of hematopoietic cell lineages. Different factors such as genetic backgrounds, viruses, chemicals, and radio waves induce leukemia. Leukemia is the sixth leading cause of cancer related mortality. ${ }^{1}$ Radiotherapy, chemotherapy, stem cell transplantation, and immunotherapy are the most common therapeutic approaches in leukemia treatment. ${ }^{2}$ However, the lack of an effective and relatively non-toxic treatment is obvious despite the improvement in the knowledge in respect to leukemia pathogenesis. In addition to different gene mutations, various epigenetic factors such as noncoding RNAs also play an essential role in the development of leukemia. Micro-RNAs (miRs) are the most well-known non-coding RNAs. miRs are small single-strandedendogenous RNAs with important roles in gene regulation through disrupting the expression of target genes. ${ }^{3}$ Additionally, these 19-22 bp nucleotide molecules are involved in different biological processes such as growth, proliferation, differentiation, and cell death. ${ }^{4,5}$ Different experimental studies proved the critical role of miRs in cancer development, progression, and metastasis. ${ }^{6,7}$ Also, miRs play critical roles in different processes of hematopoiesis such as lineage differentiation and commitment, apoptosis, and cell function. Therefore, any change in miRs expression signature can have make a significant impact on different biological processes of cells. ${ }^{8}, 9$

MiR-9 was discovered as a vital regulator of organ growth and neurogenesis. ${ }^{10}$ Subsequently, further studies showed that MiR-9 dysregulation might occur in various cancers. Therefore, MiR-9 is suggested to be an oncogene or a tumor suppressor. Three independent MiR-9 genes are identified in humans, including MiR-91 on chromosome 1, MiR-9-2 on chromosome 5, and MiR-9-3 on chromosome $15 .{ }^{11}$ Overexpression of MiR-9 has consequently been observed in Hodgkin's lymphoma, primary brain tumor, CDX2-negative gastric cancer, and endometrial cancer, while its downregulation has been observed in cervical, colorectal, lung, ovarian, and hepatocellular cancers, which suggests its oncogenic roles. ${ }^{12-21}$ On the other hand, MiR-9 silencing through the methylation of cytosine-phosphate-guanine Islands (CPG) was observed in many cancers, which clarifies its tumor suppression features. ${ }^{13,21-25}$ Furthermore, downregulation of MiR-9 is a marker of poor prognosis in cervical and lung cancers as well as acute lymphoblastic leukemia (ALL). ${ }^{18,21,25}$ Therefore, it seems that MiR-9 has a two-faced role in cancers as tumor suppressor and tumor inducer. MiR-9 has been detected in hematopoietic stem cells (HSCs) and progenitors. Moreover, its expression has been shown to increase during hematopoietic differentiation. However, the 
aberrant expression of MiR-9 clearly steps up terminal myelopoiesis and induces apoptosis. Conversely, its inhibition blocks myelopoiesis. ${ }^{26}$ Finally, these observations raise the question of which of the MiR-9 faces are enrolled in leukemia. Therefore, this study aims to evaluate the distinct role of MiR-9 in leukemia pathogenesis. We have attempted to show the prognostic impact of MiR-9 in leukemia. The potential of MiR-9 as a therapeutic target in leukemia was also reviewed.

\section{MiR-9 and cell cycle}

Leukemia is derived from the accumulation of mutations in oncogenes or tumor suppressor genes as well as disruption of balance between proliferation and differentiation in hematopoietic progenitor cells' pool. ${ }^{27,28}$ Hematopoietic homeostasis causes balanced proliferation and differentiation in different levels of hematopoiesis such as HSCs self-renewal, progenitors' proliferation, and terminal differentiation of mature blood cells. In fact, leukemic transformation is a type of disrupted balance in which proliferation predominates differentiation. ${ }^{29}$ Thus, the cell cycle regulators play a key role in the control of these processes..$^{30} \mathrm{Cell}$ cycle is controlled by various transcription factors; therefore, the heterogeneity of stem cells depends on the type of transcription factors expressed in stem cells. ${ }^{31}$ Cell cycle is a highly precise process and occurs in response to specific cell or tissue requirements. Cyclin-dependent kinases (Cdks) and their cyclins, which are considered as the second part of Cdk holoenzymes, are among the most important regulators of cell cycle. Cdks include nine proteins, which are activated or inactivated through their threonine phosphorylation by Cdk activator kinase or dephosphorylation by cdk phosphatase, respectively. Based on their function, cyclins are divided into three categories of G1-S cyclins, S cyclins, and M cyclins. ${ }^{32}$ Cdks activity is regulated at transcriptional and posttranscriptional levels. ${ }^{33}$ It has been indicated that miRs play an important role in cell cycle regulation, and several miRs have been reported to regulate cell cycle. ${ }^{34} \mathrm{MiR}-9$ mostly targets proteins that are involved in cell cycle. Therefore, it has been hypothesized that one of the most important tumorigenic mechanisms of MiR-9 dysregulations may be done through cell cycle disruption. Subsequently, the role of miR-9 targets that act as cell cycle regulators will be discussed in normal and malignant hematopoiesis.

\section{Cell cycle induction}

Cyclin D1 activates its cognates (i.e. Cdk4/Cdk6) in response to mitogenic growth factors and leads to cell cycle progress from the beginning to mid G1 phase. Cyclin-D1 dependent kinase inactivates retinoblastoma $(\mathrm{Rb})$ tumor suppressor through a phosphorylation-dependent mechanism. ${ }^{35}$ Cyclin-D1, which is a target of miR-9, plays an essential role in normal hematopoiesis in addition to its important role in cell cycle. ${ }^{36,37}$ Although cyclin-D1 expression in Acute Myeloid leukemia (AML) patients is not significantly different with normal individuals, patients with acute lymphoblastic leukemia (ALL) show a remarkable overexpression of Cyclin-D1. ${ }^{38}$ Moreover, its overexpression has been reported in the accelerated phase of CML. ${ }^{39}$

Anaphase-promoting complex/cyclosome (APC/C) is a multifunctional ubiquitin-protein ligase regulating the cell cycle. APC/C activation depends on cell division cycle protein $20(\mathrm{Cdc} 20)$ and Cadherin-1 (Cdh1). Cdc20 activates APC/C in early stages of mitosis while Cdh1 (also known as E-cadherin) has a significant role in late stages of mitosis and G1/S transition. ${ }^{40} \mathrm{APC} / \mathrm{Cdh} 1$ plays a role in genomic stability and cell cycle transition, as well as regulating cell differentiation in addition to its role in cell cycle control. Cdh1 downregulation has been indicated in several hematologic neoplasias and solid tumor cell lines. ${ }^{41} \mathrm{Cdh} 1$ expression is essential in erythroblastic maturation as its expression decreases in leukemic blast cells, and Cdh1 expression reduction has been detected in various acute and chronic leukemias such as AML, ALL , chronic myeloid leukemia (CML), and chronic lymphocytic leukemia (CLL). ${ }^{42,43}$ It has been reported that Cdh1 downregulation is caused by hypermethylation in $70 \%$ of cases. ${ }^{42} \mathrm{Cdh} 1$ is reported to be a direct target of MiR-9. ${ }^{24}$ Meanwhile, MiR-9 can be another important regulator of Cdh1.

ETS proto-oncogene 1 (Ets-1) is another target of MiR-936 as well as a prototype of ETS transcription factors family that is involved in many biological functions. ${ }^{44}$ Ets-1 facilitates G1/Sphase transition through the upregulation of Cyclin E and CDK2 genes. ${ }^{45}$ Additionally, Ets- 1 inhibits $\mathrm{CD} 34^{+}$cell proliferation by reducing cylin D3 expression. ${ }^{46}$ Therefore, Ets-1 plays an important role in cell cycle regulation. On the other hand, Ets- 1 has been shown to be capable of inducing apoptosis in tumor cells through regulating caspase- 1 expression. ${ }^{47,48}$ According to the dual role ofEts-1 in various cells, the accurate regulation of its expression is of importance in cell fate. Assessment of the Ets-1 role in hematopoiesis indicates its importance in proliferation and differentiation of different blood cells. Ets-1 downregulation leads to granulocytes differentiation, ${ }^{49}$ and it has been reported to be a differentiation regulator of plasma cells as well as B cells. Increase in Est-1 expression is known to be required for B-cell maturation; however, its expression should be reduced for plasma cell differentiation. ${ }^{50}$ Also, the role of this transcription factor has been evaluated in regulating erythroid/megakaryocyte differentiation. Est-1 overexpression in hematopoietic progenitors blocks erythroid differentiation and induces the differentiation progress towards megakaryocyte lineage. ${ }^{51}$ The important point about Ets-1 is its overexpression in AML patients' blasts and erythroleukemia cell lines. ${ }^{49,51}$ Additionally, it has been identified that the overexpression of MiR-9 leads to reduced expression of Ets related gene (ERG), a poor prognosis marker in AML, which consequently increases remission and reduces the diseases relapse. ${ }^{52}$

Nuclear factor kappa-light-chain-enhancer of activated B cells (NFkB) transcription factor family that includes NFkB1, NFkB2, Rel-a, Rel-b, and Rel-c stimulates the expression of proteins involved in cell growth, proliferation, differentiation, as well as immune and inflammation response. ${ }^{53}$ Increase in NFkB activity leads to cell cycle progression through transcriptional activation of cyclin D1 gene and increasing Cdk-D1 activity. Moreover, this transcription factor inhibits terminal differentiation in mammalian cells. ${ }^{54}$ NFkB1 plays a key role in hematopoiesis; consequently, this transcription factor contributes to the differentiation and activation of macrophages, granulocytes, osteoblasts, dendritic cells, and erythrocytes, and the involvement of NFkB1 has been demonstrated in lymphopoiesis, too. ${ }^{55}$ It seems that NFkB also plays a role in apoptosis inhibition. Recent studies illustrated that NFkB inhibition could promote apoptosis in granulocytes and lymphocytes. ${ }^{55,56}$ Although NFkB expression is considered to be an important factor in survival of normal cells, its apoptosis inhibitor role in tumor cells can be an obstacle in the treatment of leukemia patients. It has been indicated that NFkB inhibition can increase apoptosis in leukemic cell lines and ALL patients. ${ }^{57,58}$ Also, the overexpression of NFkB has been shown in hematologic malignancies, particularly AML. ${ }^{59}$ Several drugs have been suggested for NFkB inhibition and apoptosis induction in cancer cells. ${ }^{57-59}$ Because of the regulatory effect of MiR-9 on NFkB, its induction might affect NFkB expression. ${ }^{60}$ However, further experiments are required to prove this hypothesis. 
Serum response factor (SRF) is a transcription factor that regulates the expressions of various genes and regulates different cellular activities such as proliferation, differentiation, angiogenesis, migration, and apoptosis. ${ }^{61}$ It has been reported that the constitutive expression of SRF protein is sufficient to initiate cell cycle. Moreover, it was shown that PI3K-dependent cell cycle progression was associated with SRF activation and subsequent SFRrelated gene expression. ${ }^{62}$ Additionally, SRF has been recognized as an essential factor in HSCs homeostasis. Furthermore, it seems that SRF plays a role in AML through its co-activator, i.e. T-cell differentiation protein (MAL). ${ }^{63}$ This transcription factor is also one of the MiR-9 targets. ${ }^{64}$ According to our knowledge, there are few studies with respect to SRF evaluation in hematologic neoplasms. Therefore, SRF expression in these patients can give us valuable information about its role in blood malignancies.

\section{Cell cycle arrest}

Forkhead box protein O1 (FOXO1), a member of Forkhead family transcription factors, regulates the expressions of a large number of genes that play a critical role in cell cycle and apoptosis. ${ }^{65}$ FOXO induces $\mathrm{p} 21^{\mathrm{Cip} 1}$ expression, decreases cyclin D1 and D2 expressions and also increases cyclin G2 and P130 expression. Cell passage from G0 to $\mathrm{G} 1$ phase requires increase in cyclin D expression and $\mathrm{p} 21^{\mathrm{Cip} 1}$ degradation. However, the increase in cyclin G2 and P130 expression is seen in quiescence cells. ${ }^{66}$ Thus, FOXO's function is to keep the cell in G0 phase, which leads to cell cycle arrest. FOXO induces arrest in G2 through regulating the expression of Growth Arrest and DNA Damage-inducible 45 (GADD45). ${ }^{67}$ and is also essential in the maintenance of hematopoietic cells. In addition to FOXO1, FOXO3, which is another member of this family, regulates a cell cycle inhibitor factor called p27 Kip1 and also downregulates the expression of CDK2, cyclin D1, and proliferating cell nuclear antigen (PCNA). ${ }^{68}$ However, Akt signaling pathway is considered as the most important regulator of these factors. Recently, other pathways have been noticed in hematopoiesis. ${ }^{69}$ FOXOs areoverexpressed in $40 \%$ of AML patients regardless of their genetic subtypes, and their expression is required to maintain leukemic initiating cells (LICs). It has been shown that FOXO inhibition can lead to myeloid maturation and subsequent AML cell death. ${ }^{70}$ Moreover, FOXO1 overexpression is reported to be a key factor in BCR-ABL1-independent drug resistance in CML patients. ${ }^{71}$ Recently, studies have shown that B-ALL cells have a high expression level of FOXO1 which regulates their survival. ${ }^{72}$ Hence, FOXO1 is proposed to be a therapeutic target in these neoplasias. Nevertheless, FOXO3 plays various roles in different hematopoietic neoplasms but its expression increases in AML, and it is suggested to act as an oncoprotein in AML patients. BCR-ABL1 positive patients showed a downregulation of FOXO3. ${ }^{73,74}$ FOXO1 and FOXO3 are targets of MiR-9, ${ }^{75}$ and these findings generally raise the question of whether inducing MiR-9 expression through reducing FOXO expression affects apoptosis process in leukemic cells. The answer to this question requires experimental studies.

Cyclin G1 (CCNG1), a P53 target gene, operates in P53dependent and independent manners. ${ }^{76}$ CCNG1 is associated with CDK5 and non-CDK-serine/threonine kinase (cyclin G associated kinase). It acts as an oncogene, and its overexpression has been observed in human cancer cells. Also, this protein is involved in G2/M arrest induced by DNA damage. ${ }^{77,78}$ However, the distinct role of CCNG1 in hematopoiesis and hematologic malignancies has not been defined, and the authors reported that its overexpression in acute leukemia patients was associated with apoor prognosis. ${ }^{79}$ CCNG1 has been known as a validated target of MiR-9. ${ }^{80}$

Transforming Growth Factor $\beta 1$ (TGF- $\beta 1$ ) is a member of a growth factors family that inhibits cell cycle in various types of human cells. TGF- $\beta 1$ arrests cell cycle at G1 through smads, which regulates different transcriptional targets including $\mathrm{C}$-myc. C-myc downregulation induces $\mathrm{p} 15^{\mathrm{INK} 4 \mathrm{~b}}$, which is a Cdk4-cyclin D inhibitor. Furthermore, TGF- $\beta 1$ inhibits cdk2-cyclin through p27 Kip1 ${ }^{81}$ Therefore, TGF- $\beta 1$ arrests the cells in G1 phase through the aforementioned mechanisms. This growth factor inhibits the proliferation of quiescent hematopoietic cells and stimulates the differentiation of late progenitors to erythroid and myeloid cells. Additionally, TGF- $\beta 1$ leads to tumor growth and survival through affecting the tumor microenvironment. ${ }^{82}$ Aberrantlyincreased production of TGF- $\beta 1$ promotes leukemia development through inducing fibrosis in bone marrow (BM). In these circumstances, additional secretion of TGF- $\beta 1$ from leukemic cells, monocytes, and megakaryocytes stimulates collagen synthesis in fibroblasts deposited in BM. ${ }^{83}$ The overexpression of MiR-9-5p inhibits TGF$\beta 1$-mediated differentiation of fibroblasts, so that MiR-9 induction drastically decreases fibrogenesis. But, interestingly, TGF $\beta 1$ induces MiR-9 expression. ${ }^{84}$ It has been thought that there is a feedback loop between TGF $\beta 1$ and MiR-9, which means that it can either be a target of MiR-9 or induce MiR-9 expression.

\section{Other factors}

REST Corepressor 1(RCOR1), another target of MiR-9, is one of the most important transcription co-repressors expressed in HSCs as well as progenitors, which is also involved in progeny differentiation. The role of RCOR1 has been recently studied in normal hematopoiesis. It has been reported as an essential factor in normal differentiation of myeloerythroid progenitors, which regulates self-renewal activity in monocytes. ${ }^{85,86}$ More studies should be done on RCOR1 expression in leukemia patients in order to determine its role in malignant hematopoiesis.

\section{MiR-9 dysregulation in leukemia}

Few studies have been done with respect to MiR-9 expression in blood neoplasias. The findings are apparently inconsistent, and it is not easy to draw final conclusions. Chen et al. proved that MiR-9 is an essential oncogene and can even be regarded as a therapeutic target in patients with mixed lineage leukemia-rearranged (MLLr) AML ${ }^{87}$ Conversely, Emmrich et al. argued that MiR-9 is a tumor suppressor in AML patients with $\mathrm{t}(8 ; 21) .{ }^{88}$ Weinder et al. reported that MiR-9 induction by drugs in AML blasts may improve the disease outcomes. ${ }^{52}$ Theprognostic role of MiR-9 in patients with ALL is conflicting. Otero et al. emphasized that MiR9 is hypermethylated in 54\% of ALL patients and its consequent reduction is associated with a poor prognosis. ${ }^{25}$ Sugita et al. presented documents that MiR-9 overexpression was observed in $20 \%$ of patients with ALL and that it was a poor prognosis predictor in these patients. ${ }^{89}$ In order to clarify these paradoxical studies, a review was carried out and showed that AML patients with favorable cytogenetic findings such as $\mathrm{t}(8 ; 21)$, inv(16), and $\mathrm{t}(15 ; 17)$ had a low expression level of MiR-9 while AML patients with adverse or intermediate cytogenetic risk showed MiR-9 overexpression. ${ }^{90}$ Therefore, genetic aberrations could determine the prognostic role of MiR-9 in ALL patients. Additionally, determining the prognostic and pathogenic roles of validated targets of MiR-9 can designate its role in the development, progression, and outcome of leukemia.

The overexpression of a majority of MiR-9 targets strongly correlates with the development of hematologic malignancies. These targets include Peripheral myelin protein 22 (PMP22), 
Sirtuin 1 (Sirt1), ETS Proto-Oncogene 1 (Ets1), Stathmin 1 (STMN1), and Caudal Type Homeobox 2 (CDX2). ${ }^{20,36,49,91-97}$ PMP22 is an oncogene, which is observed in neoplastic processes of prostate and breast cancers. This oncogene plays an important role in leukemic stem cells growth and survival. ${ }^{98-100}$ Liu et al. showed that PMP22 expression level in cells isolated from CML patients was significantly higher than the control group. They also proved that PMP22 knockdown could inhibit the proliferation of CML cells, decrease bcl-xl expression, increase caspase-3 expression, and finally increase neoplastic cells' apoptosis. ${ }^{97}$

SIRT1 is a deacetylase that selectively deacetylates histone H4K16 and H1K26, which subsequently plays a role in gene silencing and heterochromatin formation. ${ }^{101-103}$ SIRT1 affects various cell processes through affecting different genes such as p53, FOXO1, FOXO3a, NF-kB, C-MYC, N-MYC, and E2F1 expressions. ${ }^{104,105}$ SIRT1 expression increases in various blood malignancies such as ALL, CLL, CML, and AML. ${ }^{106-109}$ Moreover, recent experiments indicated that SIRT1 inhibition by a drug or through RNA interference leads to disease remission via increased expression of $\mathrm{p} 53 .{ }^{106-109}$

Ets-1 is a member of ETS family of transcription factors. Ets1 plays an important role in cell proliferation, apoptosis, transformation, differentiation, angiogenesis, and hematopoiesis. Ets-1 expression increases in various human tumors and has prognosis value in malignancies. ${ }^{110}$ Increase in Ets-1 expression has been observed in malignant T-cells as well as cells isolated from AML patients. ${ }^{111-113}$

STMN1 is a microtubules destabilizer that has an important role in cell cycle progression, chromosome segregation, clonogenicity, cell movement, and survival. Studies suggest that STMN1 is overexpressed in malignant hematopoietic cells and that its inhibition reduces the proliferation of leukemic cell line. ${ }^{96}$

CDX2 gene is located on chromosome 13q12.12 and encodes a transcription factor, which plays a role in hematopoiesis and embryonic organogenesis in vertebrates. Initial studies showed that theaberrant expression of CDX2 is probably associated with metaplasia in gastrointestinal tract tumors. ${ }^{114,115}$ Consequently, research on hematologic malignancies provided interesting results, and numerous studies showed that CDX2 gene was aberrantly expressed in a variety of hematologic malignancies such as ALL, AML, and CML. ${ }^{116-118}$

Basic-helix-loop-helix (bHLH) family of transcription factors has a role in cell differentiation, including the differentiation of $\mathrm{B}$ and $\mathrm{T}$ lymphocytes. Inhibitor of DNA binding (ID) is another group of proteins belonging to HLH family and classified as ID-1 to ID-4 types. ID proteins attach to both classes of b-HLH and inhibit their binding to DNA. ${ }^{119}$ Among ID proteins, ID-2 is known as the MiR-9 target. ${ }^{120}$ ID-2 (but not ID-3) can attach to all the three pRb family members including pRb, p10, and p130 to abolish their growth-suppressing activity. Therefore, ID2 acts as an antagonist of several tumor suppressors ${ }^{121}$ and has an important role in hematopoiesis. It has been shown that ID2 is expressed in mature myeloid blast cells and that its expression is increased in terminal differentiation of myeloid cells. ${ }^{122}$ ID2 expression significantly increases in acute leukemias. ${ }^{123}$ Recently, some pieces of evidence have suggested the pro-survival function of ID2 in chronic lymphocytic leukemia cells. ${ }^{124}$

\section{MiR-9 regulation}

There are few studies about MiR-9 regulatory factors. Davila et al. recently demonstrated that MiR-9 promoter contains two binding sites for myocyte enhancer factor 2C (Mef2C) transcription factor and that its exclusive inhibition reduces the activity of MiR-9 promoter. ${ }^{125}$ Mef2C oncogenic role has been reported in hematological cancers, and it is identified as a well-characterized oncogene. ${ }^{126}$ Aberrant Mef2C expression is observed in $20 \%$ of myeloid malignancies, and its expression increase is associated with a poor prognosis in AML. ${ }^{127,128}$ Increase in Mef2C expression is one of the prominent features of immature T-cell acute lymphoblastic leukemia. ${ }^{129}$ The Mef2C is activated by ISL LIM Homeobox 1 (ISL1), and Growth Factor Independent 1B Transcriptional Repressor (GFI1B), Histone deacetylases (HDACs), homeodomain interacting protein kinase 2 (HIPK2), NK2 Homeobox 5 (NKX2-5) are major inhibitors of Mef2C. ${ }^{130}$ Mef2C activation is regulated by 38 MAPK-dependent phospho-

Table 1. Some known drugs that interact with MiR-9 regulators.

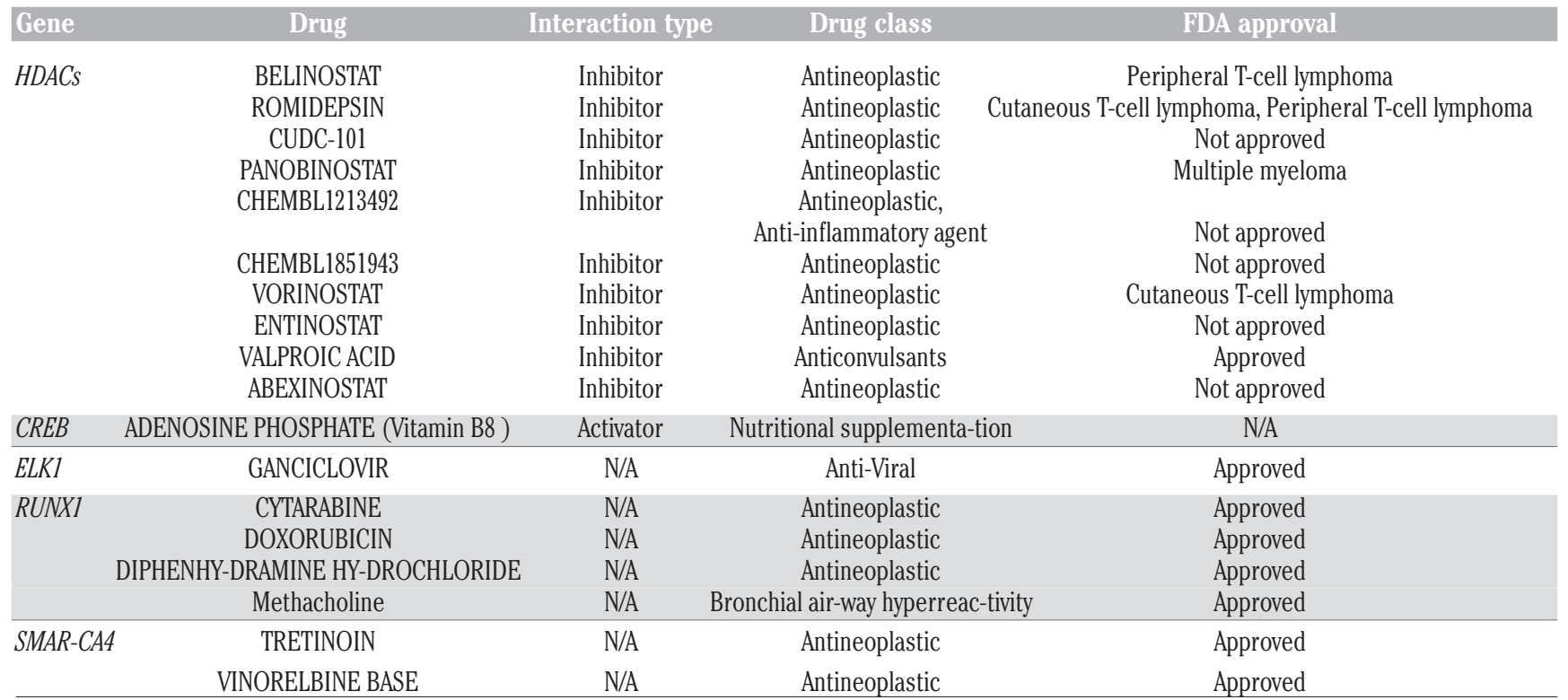

HDACs, Histone deacetylases; CREB, cAMP response element binding; ELK1, ETS transcription factor; RUNX1, runt-related transcription factor 1; SMARCA4, SWI/SNF related, matrix associat-ed, actin dependent regulator of chromatin, subfamily a, member 4. 
rylation as well as calcium-dependent calcineurin-calmodulin pathways. ${ }^{131}$ P38 MAPK activates Mef2C through phosphorylating Mef2 transcription activation domain, while calcium calmodulin-dependent protein kinase (CaMK) stimulates Mef2 activity through dissociating class II histone deacetylases (HDACs) from DNA binding-domain. The maximum activity of Mef2 is only achieved by HDACs inhibition through CaMK signaling pathway. ${ }^{132}$

The role of P38 MAPK activity in hematologic malignancies is not well understood. ${ }^{133}$ According to our knowledge, P38 MAPK activity has only been shown in B-CLL cell survival. ${ }^{134}$ However, the increase in expression and enzymatic activity of HDACs has been reported in various hematologic malignancies. Bradbury et al. showed that the increase in HDAC2 expression can be observed in most AML patients. ${ }^{135}$ Moreover, its overexpression in T-ALL and CLL has also been reported. ${ }^{136}$ Additionally, the role of HDACs inhibitors (HDACi), especially HDAC2i, in blood neoplasia treatment has been shown. ${ }^{137-139}$ Therefore, it seems that MiR9 dysregulation occurs as a result of aberrantly increased HDACs expression or activity that subsequently decreases Mef2C activity. Moreover, it is thought that one of the important mechanisms of hematologic malignancies treatment by HDAC2 inhibitors can be achieved by restoring Mef2c activity, which consequently increases MiR-9 expression. Nevertheless, experimental studies are required to confirm this hypothesis.

Cyclic adenosine monophosphate response-element binding protein (CREB), a leucine zipper transcription factor, regulates various cellular processes such as proliferation, differentiation, and cell survival. ${ }^{140}$ It has been reported that CREB can bind to MiR9 promoter and induce its expression. Moreover, it has also been shown that CREB knockdown leads to approximately $60 \%$ decrease in MiR-9-2 level. ${ }^{141}$ The role of CREB in normal and malignant hematopoiesis has been evaluated by many studies. ${ }^{142-}$ 145 Overexpression of CREB leads to increased proliferation and survival of myeloid cells. Nevertheless, CREB induction also promotes myeloproliferative disease. Therefore, CREB can be regarded as a proto-oncogene regulator of hematopoiesis that contributes to the leukemia progression. ${ }^{143}$ BM samples of AML or ALL patients showed a higher expression level of CREB than control $\mathrm{BM}$, nonleukemic patients or during leukemia remission. ${ }^{142}$ Moreover, it was also shown that CREB overexpression could predict early relapse and a poor outcome in AML patients. ${ }^{143-145}$ CREB expression alteration leads to MiR-9 dysregulation and could be considered as an important part of CREB leukemia promoting process. Other regulators are reported to control MiR-9 expression. Snyuk et al. reported that Ectopic viral integration site 1 (EVI1) inhibits MiR-9 through MiR-9 promoter hypermethylation. ${ }^{87}$ The transcription activators of EVI1 are ELK1, RUNX1, and SMARCA4, which can be targeted by some approved and non-approved drugs (Table 1). Furthermore, MLL fusion protein directly targets MiR-9 and significantly increases its expression. ${ }^{87}$

Table 2. Some of the Mir-9 targets dysregulated in leukemia.

\begin{tabular}{|c|c|c|c|c|}
\hline Gene & Location & Function & xpression in leuke-mia & Ref. \\
\hline \multirow[t]{3}{*}{ CDH1 } & $16 \mathrm{q} 22.1$ & It is a calcium-dependent cell-cell adhesion protein & AML $\downarrow$ & 58,151 \\
\hline & & & ALL $\downarrow$ & \\
\hline & & & CML $\downarrow$ & \\
\hline ETS1 & $11 \mathrm{q} 24.3$ & Functions either as a transcriptional activator or repressor of numerous genes & AML $\uparrow$ & 49 \\
\hline NFKB1 & $4 \mathrm{q} 24$ & $\begin{array}{l}\text { Activated NFKB translocates into the nucleus and stimulates the expression of genes in-volvec } \\
\text { in a wide variety of biological func-tions. }\end{array}$ & $\begin{array}{l}\text { AML } \uparrow \\
\text { ALL } \uparrow \\
\text { CML } \uparrow \\
\text { CLL } \uparrow\end{array}$ & 59 \\
\hline FOXO1 & $13 q 14.11$ & It may play a role in myogenic growth and differentiation & $\begin{array}{l}\text { AML } \uparrow \\
\text { ALL } \uparrow \\
\text { CML } \uparrow\end{array}$ & $70-72$ \\
\hline CDX2 & $13 q 12.2$ & $\begin{array}{l}\text { Major regulator of intestine-specific genes involved in cell growth and differentiation. } \\
\text { Aberrant expression of this gene is associated with intestinal inflammation } \\
\text { and tumorigene-sis }\end{array}$ & $\begin{array}{l}\mathrm{AML} \uparrow \\
\mathrm{ALL} \uparrow \\
\mathrm{CML} \uparrow\end{array}$ & $116-118$ \\
\hline CCNG1 (cyclin G1) & 1) $5 \mathrm{q} 34$ & $\begin{array}{l}\text { It is a member of the cyclin family and con-tains the cyclin box that may be regulated } \\
\text { by P53 }\end{array}$ & Acute leukemia $\uparrow$ & 79 \\
\hline SIRT1 & 10q21.3 & $\begin{array}{l}\text { May function as an intracellular regulatory protein with mono-ADP-ribosyltransferase } \\
\text { activity }\end{array}$ & Leukemia $\uparrow$ & 96 \\
\hline ID2 & $2 p 25.1$ & $\begin{array}{l}\text { Inhibitor of DNA binding family, members of which are transcriptional regulators that } \\
\text { contain a helix-loop-helix (HLH) domain but not a basic domain }\end{array}$ & $\begin{array}{c}\text { Myeloid and } \\
\text { Lymphoid leukemia } \uparrow\end{array}$ & 123 \\
\hline FOXO3 & $6 \mathrm{q} 21$ & $\begin{array}{l}\text { Functions as a trigger for apoptosis through expression of genes necessary } \\
\text { for cell death }\end{array}$ & $\begin{array}{l}\text { ALL } \uparrow \\
\mathrm{CML} \uparrow \\
\mathrm{AML} \uparrow\end{array}$ & $70-72$ \\
\hline CCND1 & 11q13.3 & $\begin{array}{l}\text { Functions as a regulatory subunit of CDK4 or CDK6, the activity of which is required } \\
\text { for cell cycle } \mathrm{G} 1 / \mathrm{S} \text { transition }\end{array}$ & $\begin{array}{l}\text { ALL } \uparrow \\
\text { AML } \\
\text { CML } \uparrow\end{array}$ & $38-39$ \\
\hline
\end{tabular}

ETS1, ETS proto-oncogene 1; NFKB1, nuclear factor kappa B subunit 1; FOXO1, orkhead box 01; CDX2, caudal type homeobox 2; CCNG1, cyclin G1; SIRT1 sirtuin 1; ID2, inhibitor of DNA binding 2; FOXO3, forkhead box 03; CCDN1, cyclin D1. 


\section{In silico analysis of MiR-9 in leukemia}

In the next part, we have mined MiR-9 expression data from public databases (Figure 1). Recently, Tan et al. performed a noncoding RNA profiling array in order to show MiR signature in leukemic cells compared to normal cells. ${ }^{146}$ We used the available data on GEO database by mining the expression of MiR-9. The results showed that myeloid leukemia cells had a significantly lower expression level of MiR-9 compared to normal myeloid cells $(\mathrm{P}=0.045)$ (Figure 2). In another analysis, we have compared the leukemic cells of B-ALL patients with normal B-cells. Similarly the MiR-9 expression was lower in ALL leukemic cells but the differences was not statistically significant $(\mathrm{P}=0.55)$ (Figure 3). Moreover, it was found that MiR-9 expression was significantly lower in patients with T-ALL compared with normal T-cells $(\mathrm{t}=$ 2.068, $\mathrm{P}=0.048$ ) (Figure 4). Therefore, it seems that MiR-9 could be considered as a tumor suppressor in leukemic patients.

After determining the expression of MiR-9 in different leukemias, we have tried to find the relationship of MirR-9 expression with survival of leukemia patients using PROGmiR database. ${ }^{147}$ As shown in Figure 5, a high expression level of MiR-9 significantly reduced survival rate of AML patients $[\mathrm{P}=0.049$, haz- ard ratio=1.07 (1-1.14)]. This finding might show the prognostic value of MiR-9 expression in patients with AML. More studies are needed to find out the prognostic value of MiR-9 in other leukemia types.

\section{Discussion and future prospective}

miRs regulate gene expression, and any alteration of them may lead to cancer development. ${ }^{148}$ Previous studies prove important roles of miRs in cancer progression. ${ }^{149,150}$ For a long time, MiR-9 was considered as an important regulator in neurogenesis and nerve tissue development. ${ }^{10}$ This was followed by further studies, which investigated MiR-9 dysregulation role in various cancers. The distinct role of MiR-9 is related to cancer type, so MiR-9 plays a tumor suppressor role in some cancers and an oncogenic role in others. ${ }^{11}$ Recently, MiR-9 expression is discussed in various hematologic neoplasms with paradoxical roles. To solve this problem, we initially studied validated MiR-9 targets in cell cycles of normal and malignant hematopoiesis. The results indicated that MiR9 targeted cell cycle-promoting genes such as cyclin D1, Ets, $\mathrm{NFkB}, \mathrm{Cdh} 1, \mathrm{SRF}$, as well as cell cycle inhibitors such as FOXO1

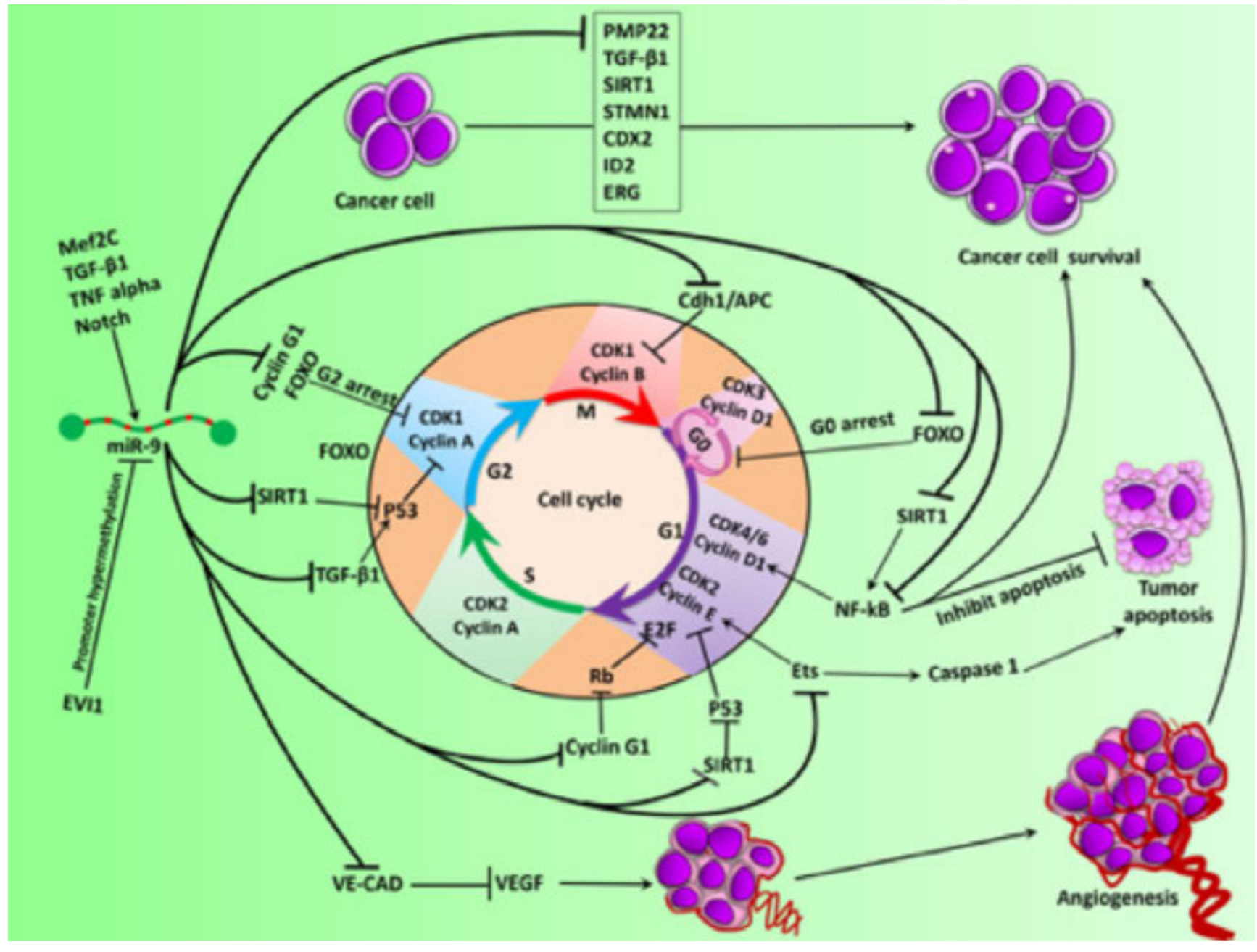

Figure 1. Summary of miR-9 targets and functions. MiR-9 affects different cell cycle mole-cules, cancer cell survival, apoptosis, and angiogenesis. Hence, maybe miR-9 targeting mole-cules can explain tumor suppressor or tumor initiator effect of miR-9. 
and Cyclin G1. ${ }^{24,36,37,60,64,75,80}$ Overall, MiR-9 has a dual role in cell cycle regulation. These findings point out that MiR-9 dysregulation disturbs normal cell cycle. MiR-9 targets dysregulation, which has been proven in myeloid and lymphoid neoplasms. Therefore, MiR-9 dysregulation may lead to leukemia development through disrupting the expression of its targets. Interestingly, among the validated MiR-9 target genes dysregulated in hematologic malignancies, only $\mathrm{Cdh} 1$ is downregulated in three leukemic lineages (Table 2). ${ }^{151,152}$ However, it has been reported that Cdh1 hypermethylation is the main reason for its downregulation and that the role of other epigenetic regulators is inconsiderable. ${ }^{42}$ Based on these findings, MiR-9 downregulation and subsequent overexpression of its targets is more likely to cause leukemic progression and might act as a tumor suppressor in hematologic

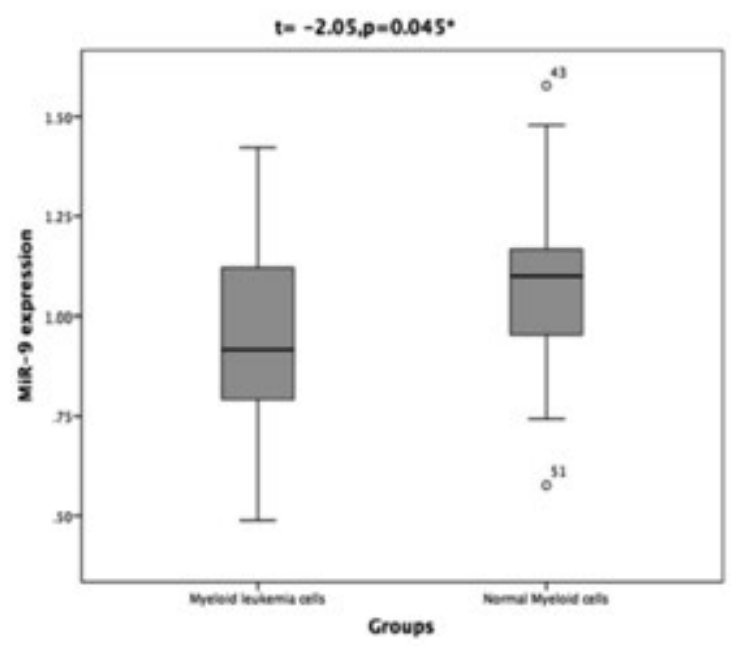

Figure 2. MiR-9 expression comparison in myeloid leukemia cells and normal myeloid cells.

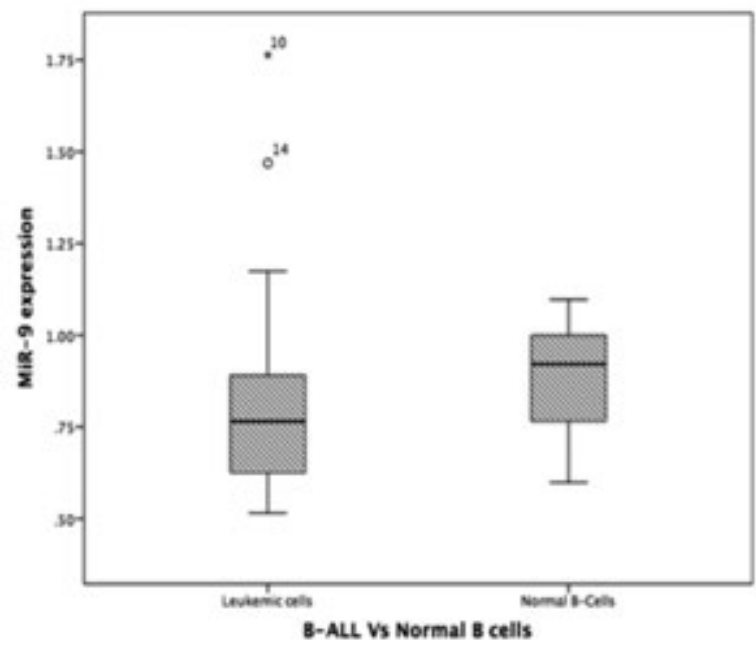

Figure 3. MiR-9 expression in B-ALL leukemic cells compared to normal B-cells. malignancies. Our analysis on mined data from public databases also confirmed these findings later. However, oncogenic role of MiR-9 in hematologic malignancies was also reported in patients with MLLr. ${ }^{87}$ Thus, there are two hypotheses as follows: i) The tumor suppressor or oncogenic role of MiR-9 is likely associated with the involved cell lineage and other genetic abnormalities such as MLLr; ii) It is also likely that excessive increase or decrease (i.e., dysregulation) of MiR-9 leads to leukemia development through disrupting normal hematopoiesis. Another important finding is that MiR-9 can be utilized as a prognostic factor in hematologic neoplasms. Moreover, MiR-9 pharmacological induction can be used as a therapeutic target in malignancies when MiR-9 targets expression changes. Experimentally, MiR-9 regulation was shown to be a good therapeutic target in AML patients. ${ }^{52}$

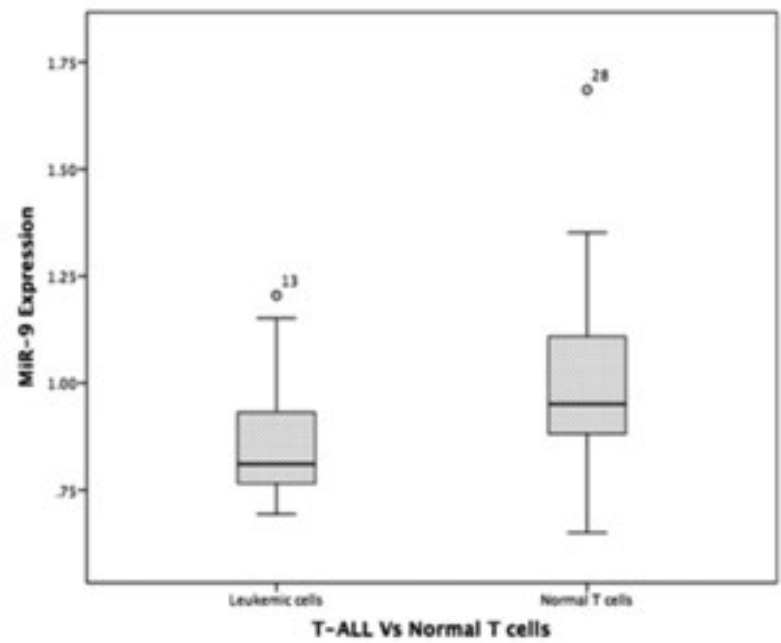

Figure 4. Comparison of MiR-9 expression in T-ALL leukemic cells and normal T-cells.

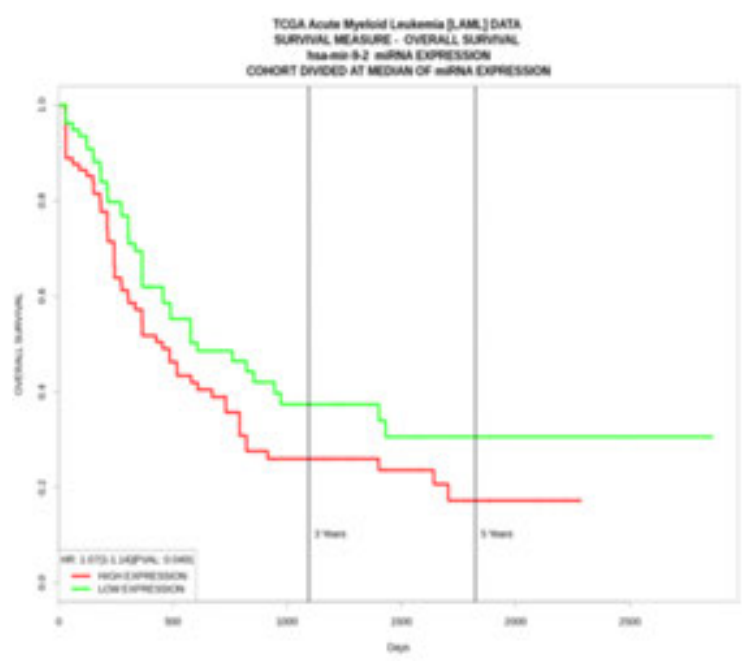

Figure 5. MiR-9 expression significantly reduces overall survival in AML patients. 


\section{Conclusions}

This study generally indicates that MiR-9 dysregulation leads to leukemia development through various targets. Tumor suppressor or oncogenic role of MiR-9 is different in various leukemia subtypes. Finally, MiR-9 has a prognostic value in leukemia, and its prognostic role has been investigated in AML and ALL. ${ }^{22,90}$ Thus, MiR-9 has an important role in hematological malignancies. In order to accurately determine the extent of MiR-9 involvement in the development of myeloid neoplasms, it is suggested to evaluate the effect of MiR-9 induction on different hematological malignancies and subsequently assess the expression of its target genes in further studies.

\section{References}

1. Napier RJ, Norris BA, Swimm A, et al. Low doses of imatinib induce myelopoiesis and enhance host anti-microbial immunity. PLoS Pathog 2015;11:e1004770.

2. Chendamarai E, Ganesan S, Alex AA, et al. Comparison of newly diagnosed and relapsed patients with acute promyelocytic leukemia treated with arsenic trioxide: insight into mechanisms of resistance. PLoS One 2015;10:e0121912.

3. Ell B, Kang Y. MicroRNAs as regulators of bone homeostasis and bone metastasis. Bone Key Rep 2014;3.

4. Bartel DP. MicroRNAs: target recognition and regulatory functions. Cell 2009;136:215-33.

5. Zhang H, Li Y, Lai M. The microRNA network and tumor metastasis. Oncogene 2010;29:937-48.

6. Di Leva G, Croce CM. Roles of small RNAs in tumor formation. Trends Mol Med 2010;16:257-67.

7. Mendell JT, Olson EN. MicroRNAs in stress signaling and human disease. Cell 2012;148:1172-87.

8. Newman MA, Hammond SM. Emerging paradigms of regulated microRNA processing. Genes Devel 2010;24:1086-92.

9. Chung SS, Hu W, Park CY. The role of microRNAs in hematopoietic stem cell and leukemic stem cell function. Ther Adv Hematol 2011;2:317-34.

10. Leucht C, Stigloher C, Wizenmann A, et al. MicroRNA-9 directs late organizer activity of the midbrain-hindbrain boundary. Nature Neurosci 2008;11:641-8.

11. Wang LQ, Kwong YL, Kho CSB, et al. Epigenetic inactivation of miR-9 family microRNAs in chronic lymphocytic leukemia-implications on constitutive activation of $\mathrm{NF} \kappa \mathrm{B}$ pathway. Mol Cancer 2013;12:1.

12. Nie K, Gomez M, Landgraf P, et al. MicroRNA-mediated down-regulation of PRDM1/Blimp-1 in Hodgkin/ReedSternberg cells: a potential pathogenetic lesion in Hodgkin lymphomas. Am J Pathol 2008;173:242-52.

13. Bandres E, Agirre X, Bitarte N, et al. Epigenetic regulation of microRNA expression in colorectal cancer. Int $\mathrm{J}$ Cancer 2009; 125:2737-43.

14. Guo LM, Pu Y, Han Z, et al. MicroRNA $\square 9$ inhibits ovarian cancer cell growth through regulation of $\mathrm{NF} \square \kappa \mathrm{KB}$. FEBS J 2009;276:5537-46.

15. Luo H, Zhang H, Zhang Z, et al. Down-regulated miR-9 and miR-433 in human gastric carcinoma. J Exper Clinical Cancer Res 2009;28:1.

16. Nass D, Rosenwald S, Meiri E, et al. MiR $\square 92 b$ and miR $\square 9 / 9 *$ are specifically expressed in brain primary tumors and can be used to differentiate primary from metastatic brain tumors. Brain Pathol 2009;19:375-83.
17. Hao-Xiang T, Qian W, Lian-Zhou C, et al. MicroRNA-9 reduces cell invasion and E-cadherin secretion in SK-Hep-1 cell. Med Oncol 2010;27:654-60.

18. Hu X, Schwarz JK, Lewis JS, et al. A microRNA expression signature for cervical cancer prognosis. Cancer Res 2010;70:1441-8.

19. Myatt SS, Wang J, Monteiro LJ, et al. Definition of microRNAs that repress expression of the tumor suppressor gene FOXO1 in endometrial cancer. Cancer Res 2010;70:36777.

20. Rotkrua P, Akiyama Y, Hashimoto Y, et al. MiR $\square 9$ downregulates CDX2 expression in gastric cancer cells. Int J Cancer 2011;129:2611-20.

21. Heller G, Weinzierl M, Noll C, et al. Genome-wide miRNA expression profiling identifies miR-9-3 and miR-193a as targets for DNA methylation in non-small cell lung cancers. Clin Cancer Res 2012;18:1619-29.

22. Lujambio A, Calin GA, Villanueva A, et al. A microRNA DNA methylation signature for human cancer metastasis. Proc Natl Acad Sci 2008;105:13556-61.

23. Hildebrandt M, Gu J, Lin J, et al. Hsa-miR-9 methylation status is associated with cancer development and metastatic recurrence in patients with clear cell renal cell carcinoma. Oncogene 2010;29:5724-8.

24. Ma L, Young J, Prabhala H, et al. miR-9, a MYC/MYCN-activated microRNA, regulates E-cadherin and cancer metastasis. Nature Cell Biol 2010;12:247-56.

25. Rodriguez $\square$ Otero P, Román $\square$ Gómez J, Vilas $\square$ Zornoza A, et al. Deregulation of FGFR1 and CDK6 oncogenic pathways in acute lymphoblastic leukaemia harbouring epigenetic modifications of the MIR9 family. Br J Haematol 2011;155:73-83.

26. Senyuk V, Zhang Y, Liu Y, et al. Critical role of miR-9 in myelopoiesis and EVI1-induced leukemogenesis. Proc Natl Acad Sci 2013;110:5594-9.

27. Crans H, Sakamoto K. Transcription factors and translocations in lymphoid and myeloid leukemia. Leukemia 2001; $15: 313$.

28. Gamal Abdul Hamid AN. Clinicoepidemiological features of adult leukemias in Aden, Yemen. Indian J Appl Res 2015;5:7.

29. Spike BT, Macleod KF. The Rb tumor suppressor in stress responses and hematopoietic homeostasis. Cell Cycle 2005;4:42-5.

30. Aleem E, Arceci RJ. Targeting cell cycle regulators in hematologic malignancies. Front Cell Develop Biol 2015;3.

31. Singh AM, Chappell J, Trost R, et al. Cell-cycle control of developmentally regulated transcription factors accounts for heterogeneity in human pluripotent cells. Stem Cell Rep 2014;2:398.

32. Sandal T. Molecular aspects of the mammalian cell cycle and cancer. Oncologist 2002;7:73-81.

33. de Boer HR, Llobet SG, van Vugt MA. Controlling the response to DNA damage by the APC/C-Cdh1. Cell Mol Life Sci 2016;73:949-60.

34. Bueno MJ, Malumbres M. MicroRNAs and the cell cycle. Biochim Biophys Acta Mol Basis Dis 2011;1812:592-601.

35. Diehl JA. Cycling to cancer with cyclin D1. Cancer Biol Ther 2002;1:226-31.

36. Zheng L, Qi T, Yang D, et al. microRNA-9 suppresses the proliferation, invasion and metastasis of gastric cancer cells through targeting cyclin D1 and Ets1. PLoS One 2013;8:e55719.

37. Chaves-Ferreira M, Krenn G, Vasseur F, et al. The cyclin D1 carboxyl regulatory domain controls the division and differentiation of hematopoietic cells. Biol Direct 2016;11:1. 
38. Aref S, Mabed M, El-Sherbiny M, et al. Cyclin D1 expression in acute leukemia. Hematology 2013.

39. Liu J-H, Yen C-C, Lin Y-C, et al. Overexpression of Cyclin D1 in Accelerated-Phase Chronic Myeloid Leukemia. Leuk Lymph 2004;45:2419-25.

40. Skaar JR, Pagano M. Cdh1: a master G0/G1 regulator. Nature Cell Biol 2008;10:755-7.

41. Qiao X, Zhang L, Gamper AM, et al. APC/C-Cdh1: from cell cycle to cellular differentiation and genomic integrity. Cell Cycle 2010;9:3904-12.

42. Melki JR, Vincent PC, Brown RD, Clark SJ. Hypermethylation of E-cadherin in leukemia. Blood 2000;95:3208-13.

43. Jordaan G, Liao W, Sharma S. E-cadherin gene re-expression in chronic lymphocytic leukemia cells by HDAC inhibitors. BMC Cancer 2013;13:1.

44. Maroulakou IG, Bowe DB. Expression and function of Ets transcription factors in mammalian development: a regulatory network. Oncogene 2000;19:6432-42.

45. Singh AK, Swarnalatha M, Kumar V. c-ETS1 facilitates G1/Sphase transition by up-regulating cyclin $\mathrm{E}$ and CDK2 genes and cooperates with hepatitis $\mathrm{B}$ virus $\mathrm{X}$ protein for their deregulation. J Biol Chem 2011;286:21961-70.

46. Meng F-k, Sun H-y, Tan X-y, et al. Negative regulation of cyclin D3 expression by trans-cription factor c-Ets1 in umbilical cord hematopoietic cells. Acta Pharmacol Sinica 2011;32:1159-64.

47. Pei H, Li C, Adereth Y, et al. Caspase-1 is a direct target gene of ETS1 and plays a role in ETS1-induced apoptosis. Cancer Res 2005;65:7205-13.

48. Qiao N, Xu C, Zhu Y, et al. Ets-1 as an early response gene against hypoxia-induced apoptosis in pancreatic $\beta$-cells. Cell Death Dis 2015;6:e1650.

49. Lulli V, Romania P, Riccioni R, et al. Transcriptional silencing of Ets-1 oncogene contributes to human granulocytic differentiation. Haematologica 2010.

50. John SA, Clements JL, Russell LM, Garrett-Sinha LA. Ets-1 regulates plasma cell differentiation by interfering with the activity of the transcription factor Blimp-1. J Biol Chem 2008;283:951-62.

51. Lulli V, Romania P, Morsilli O, et al. Overexpression of Ets-1 in human hematopoietic progenitor cells blocks erythroid and promotes megakaryocytic differentiation. Cell Death Differ 2006;13:1064-74.

52. Weidner H, Bill M, Schmalbrock L, et al. High expression of Mir-9 down-regulates the poor outcome prognosticator erg and associates with reduced relapse-rates in acute myeloid leukemia. Blood 2014;124:1575.

53. González $\square$ Murillo Á, Fernández L, Baena S, Melen GJ, Sánchez R, Sánchez $\square$ Valdepeñas C, et al. The NFKB inducing kinase modulates hematopoiesis during stress. Stem Cells 2015;33:2825-37.

54. Joyce D, Albanese C, Steer J, et al. NF-кB and cell-cycle regulation: the cyclin connection. Cytokine Growth Factor Rev 2001;12:73-90.

55. Bottero V, Withoff S, Verma I. NF- $\kappa$ B and the regulation of hematopoiesis. Cell Death Differ 2006;13:785-97.

56. Wong HK, Tsokos GC. Fas (CD95) ligation inhibits activation of NF- $\kappa$ B by targeting p65-Rel A in a caspase-dependent manner. Clin Immunol 2006;121:47-53.

57. Wang L, Zhao S, Wang H-X, Zou P. Inhibition of NF-kappa B can enhance Fas-mediated apoptosis in leukemia cell line HL60. Front Med China 2010;4:323-8.

58. Zhang H, Zhu L, He H, et al. NF-kappa B mediated Up-regu- lation of CCCTC-binding factor in pediatric acute lymphoblastic leukemia. Mol Cancer 2014;13:1.

59. Bosman MCJ, Schuringa JJ, Vellenga E. Constitutive NF- $\kappa B$ activation in AML: Causes and treatment strategies. Crit Rev Oncol/Hematol 2016;98:35-44.

60. Rushworth SA, Murray MY, Barrera LN, et al. Understanding the role of miRNA in regulating NF- $\mathrm{KB}$ in blood cancer. Am J Cancer Res 2012;2:65.

61. Modak C. Serum response factor: look into the gut. World J Gastroenterol 2010;16:18.

62. Poser S, Impey S, Trinh $\mathrm{K}$, et al. SRF $\square$ dependent gene expression is required for PI3 $\square$ kinase $\square$ regulated cell proliferation. EMBO J 2000;19:4955-66.

63. Ragu C, Elain G, Mylonas E, et al. The transcription factor Srf regulates hematopoietic stem cell adhesion. Blood 2010;116:4464-73.

64. Buller B, Chopp M, Ueno Y, et al. Regulation of serum response factor by miRNA $\square 200$ and miRNA $\square 9$ modulates oligodendrocyte progenitor cell differentiation. Glia 2012;60:1906-14.

65. Yan L, Lavin VA, Moser LR, et al. PP2A regulates the proapoptotic activity of FOXO1. J Biol Chem 2008;283:7411-20.

66. Furukawa-Hibi Y, Kobayashi Y, Chen C, Motoyama N. FOXO transcription factors in cell-cycle regulation and the response to oxidative stress. Antioxid Redox Signal 2005; 7:752-60.

67. Yuan C, Wang L, Zhou L, Fu Z. The function of FOXO1 in the late phases of the cell cycle is suppressed by PLK1-mediated phosphorylation. Cell Cycle 2014;13:807-19.

68. Sang T, Cao Q, Wang Y, et al. Overexpression or silencing of FOXO3a affects proliferation of endothelial progenitor cells and expression of cell cycle regulatory proteins. PLoS One 2014;9:e101703.

69. Liang R, Rimmelé P, Bigarella CL, et al. Evidence for AKTindependent regulation of FOXO1 and $\mathrm{FOXO} 3$ in haematopoietic stem and progenitor cells. Cell Cycle 2016;15:861-7.

70. Sykes SM, Lane SW, Bullinger L, et al. AKT/FOXO signaling enforces reversible differentiation blockade in myeloid leukemias. Cell 2011;146:697-708.

71. Wagle M, Eiring A, Wongchenko M, et al. A role for FOXO1 in BCR-ABL1-independent tyrosine kinase inhibitor resistance in chronic myeloid leukemia. Leukemia 2016.

72. Demir S, Wang F, Gehringer F, et al. FOXO1 is involved in the regulation of $\mathrm{B}$-cell precursor acute lymphoblastic leukemia survival and serves as a novel target for directed therapy. Am Soc Hematology 2016.

73. Zhao J, Lu Q, Niu X, et al. [Expression of FoxO3a in patients with acute myeloid leukemia and its clinical significance]. Zhongguo shi yan xue ye xue za zhi/Zhongguo bing li sheng li xue hui= J Exp Hematol Chinese Assoc Pathophysiol 2013;21:847-50.

74. Zhu H. Targeting forkhead box transcription factors FOXM1 and FOXO in leukemia (Review). Oncol Rep 2014;32:132734.

75. Chen X, Zhu L, Ma Z, et al. Oncogenic miR-9 is a target of erlotinib in NSCLCs. Sci Rep 2015;5.

76. Russell P, Hennessy B, Li J, et al. Cyclin G1 regulates the outcome of taxane-induced mitotic checkpoint arrest. Oncogene 2012;31:2450-60.

77. Kimura SH, Ikawa M, Ito A, et al. Cyclin G1 is involved in G2/M arrest in response to DNA damage and in growth control after damage recovery. Oncogene 2001;20:25.

78. Seo H, Lee D, Lee H, et al. Cyclin G1 overcomes radiation- 
induced G2 arrest and increases cell death through transcriptional activation of cyclin B1. Cell Death Different 2006; 13:1475-84.

79. Chen H, Lin D, Luo L, Hu J. [Expression of P27 (kip1) and cyclin $\mathrm{G}$ in patients with acute leukemia and its correlation]. Zhongguo shi yan xue ye xue za zhi/Zhongguo bing li sheng li xue hui= J Exper Hematol Chinese Assoc Pathophysiol 2009;17:847-51.

80. Li X, Pan Q, Wan X, et al. Methylation-associated Has-miR9 deregulation in paclitaxel-resistant epithelial ovarian carcinoma. BMC Cancer 2015;15:1.

81. Mukherjee P, Winter SL, Alexandrow MG. Cell cycle arrest by transforming growth factor $\beta 1$ near G1/S is mediated by acute abrogation of prereplication complex activation involving an Rb-MCM interaction. Mol Cell Biol 2010;30:845-56.

82. Isufi I, Seetharam M, Zhou L, et al. Transforming growth factor- $\beta$ signaling in normal and malignant hematopoiesis. J Interferon Cytokine Res 2007;27:543-52.

83. Fortunel NO, Hatzfeld A, Hatzfeld JA. Transforming growth factor- $\beta$ : pleiotropic role in the regulation of hematopoiesis. Blood 2000;96:2022-36.

84. Fierro $\square$ Fernández M, Busnadiego Ó, Sandoval P, et al. miR $\square 9 \square 5$ p suppresses pro $\square$ fibrogenic transformation of fibroblasts and prevents organ fibrosis by targeting NOX4 and TGFBR2. EMBO Rep 2015;16:1358-77.

85. Yao H, Goldman DC, Nechiporuk T, et al. Corepressor Rcor1 is essential for murine erythropoiesis. Blood 2014;123:317584.

86. Yao H, Goldman DC, Fan G, et al. The corepressor Rcor1 is essential for normal myeloerythroid lineage differentiation. Stem Cells 2015;33:3304-14.

87. Chen P, Price C, Li Z, et al. miR-9 is an essential oncogenic microRNA specifically overexpressed in mixed lineage leukemia-rearranged leukemia. Proc Natl Acad Sci 2013;110:11511-6.

88. Emmrich S, Katsman-Kuipers J, Henke K, et al. miR-9 is a tumor suppressor in pediatric AML with $\mathrm{t}(8 ; 21)$. Leukemia 2014;28:1022-32.

89. Sugita F, Maki K, Nakamura Y, et al. Overexpression of MIR9 indicates poor prognosis in acute lymphoblastic leukemia. Leuk Lymph 2014;55:78-86.

90. Marcucci G, Mrózek K, Radmacher MD, et al. The prognostic and functional role of microRNAs in acute myeloid leukemia. Blood 2011;117:1121-9.

91. Scholl C, Bansal D, Döhner K, et al. The homeobox gene CDX2 is aberrantly expressed in most cases of acute myeloid leukemia and promotes leukemogenesis. J Clin Invest 2007;117:1037-48.

92. Lau P, Verrier JD, Nielsen JA, et al. Identification of dynamically regulated microRNA and mRNA networks in developing oligodendrocytes. J Neurosci 2008;28:11720-30.

93. Saunders LR, Sharma AD, Tawney J, et al. miRNAs regulate SIRT1 expression during mouse embryonic stem cell differentiation and in adult mouse tissues. Aging (Albany NY) 2010;2:415-31.

94. Chen W, Bhatia R. Roles of SIRT1 in leukemogenesis. Curr Opin Hematol 2013;20:4.

95. Song Y, Mu L, Han X, et al. MicroRNA-9 inhibits vasculogenic mimicry of glioma cell lines by suppressing Stathmin expression. J Neuro-Oncol 2013;115:381-90.

96. Machado-Neto JA, Saad S, Traina F. Stathmin 1 in normal and malignant hematopoiesis. BMB Rep 2014;47:660-5.

97. Liu H, Cao H-q, Ta J-b, et al. Knockdown of peripheral myelin protein 22 inhibits the progression of chronic myeloid leukemia. Oncol Res Feat Preclin Clinical Cancer Ther 2015;22:259-65.

98. Li J, Kleeff J, Esposito I, et al. Expression analysis of PMP22/Gas3 in premalignant and malignant pancreatic lesions. J Histochem Cytochem 2005;53:885-93.

99. Tong D, Heinze G, Pils D, et al. Gene expression of PMP22 is an independent prognostic factor for disease-free and overall survival in breast cancer patients. BMC Cancer 2010;10:1.

100. Ashton JM, Balys M, Neering SJ, et al. Gene sets identified with oncogene cooperativity analysis regulate in vivo growth and survival of leukemia stem cells. Cell Stem Cell 2012;11:359-72.

101. Imai S-I, Armstrong CM, Kaeberlein M, Guarente L. Transcriptional silencing and longevity protein Sir2 is an NAD-dependent histone deacetylase. Nature 2000;403:795800.

102. Vaquero A, Scher M, Lee D, et al. Human SirT1 interacts with histone $\mathrm{H} 1$ and promotes formation of facultative heterochromatin. Mol Cell 2004;16:93-105.

103. Vaquero A. The conserved role of sirtuins in chromatin regulation. Int J Develop Biol 2009;53:303-22.

104. Saunders L, Verdin E. Sirtuins: critical regulators at the crossroads between cancer and aging. Oncogene 2007;26:5489504.

105. Houtkooper RH, Pirinen E, Auwerx J. Sirtuins as regulators of metabolism and healthspan. Nature Rev Mol Cell Biol 2012;13:225-38.

106. Audrito V, Vaisitti T, Rossi D, et al. Nicotinamide blocks proliferation and induces apoptosis of chronic lymphocytic leukemia cells through activation of the p53/miR-34a/SIRT1 tumor suppressor network. Cancer Res 2011;71:4473-83.

107. Li L, Wang L, Li L, et al. Activation of p53 by SIRT1 inhibition enhances elimination of CML leukemia stem cells in combination with imatinib. Cancer Cell 2012;21:266-81.

108. Sasca D, Hähnel PS, Szybinski J, et al. SIRT1 prevents genotoxic stress-induced p53 activation in acute myeloid leukemia. Blood 2014;124:121-33.

109. Jin Y, Cao Q, Chen C, et al. Tenovin-6-mediated inhibition of SIRT1/2 induces apoptosis in acute lymphoblastic leukemia (ALL) cells and eliminates ALL stem/progenitor cells. BMC Cancer 2015;15:1.

110. Oikawa T. ETS transcription factors: possible targets for cancer therapy. Cancer Sci 2004;95:626-33.

111. Rücker FG, Bullinger L, Schwaenen C, et al. Disclosure of candidate genes in acute myeloid leukemia with complex karyotypes using microarray-based molecular characterization. J Clin Oncol 2006;24:3887-94.

112. Tyybäkinoja A, Saarinen $\square$ Pihkala U, Elonen E, Knuutila S. Amplified, lost, and fused genes in 11q23-25 amplicon in acute myeloid leukemia, an array $\square$ CGH study. Genes Chromos Cancer 2006;45:257-64.

113. Mrózek K, ed. Cytogenetic, molecular genetic, and clinical characteristics of acute myeloid leukemia with a complex karyotype. Seminars in oncology. Elsevier; 2008.

114. Ha Kim G, Am Song G, Youn Park D, et al. CDX2 expression is increased in gastric cancers with less invasiveness and intestinal mucin phenotype. Scand J Gastroenterol 2006; 41:880-6.

115. Wang X-T, Wei W-Y, Kong F-B, et al. Prognostic significance of $\mathrm{Cdx} 2$ immunohistochemical expression in gastric cancer: a meta-analysis of published literatures. J Exp Clin Cancer Res 2012;31:1.

116. Riedt T, Ebinger M, Salih HR, et al. Aberrant expression of the homeobox gene CDX2 in pediatric acute lymphoblastic 
leukemia. Blood 2009;113:4049-51.

117. Thoene S, Rawat V, Heilmeier B, et al. The homeobox gene CDX2 is aberrantly expressed and associated with an inferior prognosis in patients with acute lymphoblastic leukemia. Leukemia 2009;23:649-55.

118. Arnaoaut HH, Mokhtar DA, Samy RM, et al. CDX2 gene expression in acute lymphoblastic leukemia. J Egypt Natl Cancer Inst 2014;26:55-9.

119. Zebedee Z, Hara E. Id proteins in cell cycle control and cellular senescence. Oncogene 2001;20:58.

120. Annibali D, Gioia U, Savino M, et al. A new module in neural differentiation control: two microRNAs upregulated by retinoic acid, miR-9 and-103, target the differentiation inhibitor ID2. PLoS One 2012; 7:e40269.

121. Lasorella A, Iavarone A, Israel M. Id2 specifically alters regulation of the cell cycle by tumor suppressor proteins. Mol Cell Biol 1996;16:2570-8.

122. Ishiguro A, Spirin KS, Shiohara M, et al. Id2 expression increases with differentiation of human myeloid cells. Blood 1996;87:5225-31.

123. May AM, Frey A-V, Bogatyreva L, et al. ID2 and ID3 protein expression mirrors granulopoietic maturation and discriminates between acute leukemia subtypes. Histochem Cell Biol 2014;141:431-40.

124. Weiler S, Ademokun JA, Norton JD. ID helix-loop-helix proteins as determinants of cell survival in B-cell chronic lymphocytic leukemia cells in vitro. Mol Cancer 2015;14:1.

125. Davila JL, Goff LA, Ricupero CL, et al. A positive feedback mechanism that regulates expression of miR-9 during neurogenesis. PLoS One 2014;9:e94348.

126. Pon JR, Marra MA. MEF2 transcription factors: developmental regulators and emerging cancer genes. Oncotarget 2016;7:2297.

127. Canté-Barrett K, Pieters R, Meijerink J. Myocyte enhancer factor $2 \mathrm{C}$ in hematopoiesis and leukemia. Oncogene 2014;33:403-10.

128. Laszlo GS, Alonzo TA, Gudgeon CJ, et al. Erratum to: High expression of myocyte enhancer factor 2C (MEF2C) is associated with adverse-risk features and poor outcome in pediatric acute myeloid leukemia: a report from the Children's Oncology Group. J Hematol Oncol 2016;9:133.

129. Homminga I, Pieters R, Langerak AW, et al. Integrated transcript and genome analyses reveal NKX2-1 and MEF2C as potential oncogenes in $\mathrm{T}$ cell acute lymphoblastic leukemia. Cancer Cell 2011;19:484-97.

130. Han H, Cho J-W, Lee S, et al. TRRUST v2: an expanded reference database of human and mouse transcriptional regulatory interactions. Nucleic Acids Res 2017:gkx1013-gkx.

131. Kong NR, Davis M, Chai L, et al. MEF2C and EBF1 co-regulate $b$ cell-specific transcription. PLoS Genet 2016;12:e1005845.

132. Lu J, McKinsey TA, Nicol RL, Olson EN. Signal-dependent activation of the MEF2 transcription factor by dissociation from histone deacetylases. Proc Natl Acad Sci 2000;97:40705.

133. Platanias LC. Map kinase signaling pathways and hematologic malignancies. Blood 2003;101:4667-79.

134. Ringshausen I, Dechow T, Schneller F, et al. Constitutive activation of the MAPkinase p38 is critical for MMP-9 production and survival of B-CLL cells on bone marrow stromal cells. Leukemia 2004;18:1964-70.

135. Bradbury C, Khanim F, Hayden R, et al. Histone deacetylases in acute myeloid leukaemia show a distinctive pattern of expression that changes selectively in response to deacetylase inhibitors. Leukemia 2005;19:1751-9.

136. Kafeel MI, Avezbakiyev B, Chen C, et al. Histone deacetylase activity in chronic lymphocytic leukemia. Blood 2010;116:4622-.

137. Stankov MV, El Khatib M, Thakur BK, et al. Histone deacetylase inhibitors induce apoptosis in myeloid leukemia by suppressing autophagy. Leukemia 2014;28:577-88.

138. Imai Y, Maru Y, Tanaka J. Action mechanisms of histone deacetylase inhibitors in the treatment of hematological malignancies. Cancer Sci 2016.

139. Li Y, Zhao K, Yao C, et al. Givinostat, a type II histone deacetylase inhibitor, induces potent caspase-dependent apoptosis in human lymphoblastic leukemia. Genes Cancer 2016;7:292.

140. Wen AY, Sakamoto KM, Miller LS. The role of the transcription factor CREB in immune function. $\mathrm{J}$ Immunol 2010;185:6413-9.

141. Laneve P, Gioia U, Andriotto A, et al. A minicircuitry involving REST and CREB controls miR-9-2 expression during human neuronal differentiation. Nucleic Acids Res 2010;38:6895-905.

142. Crans-Vargas HN, Landaw EM, Bhatia S, et al. Expression of cyclic adenosine monophosphate response-element binding protein in acute leukemia. Blood 2002;99:2617-9.

143. Shankar DB, Cheng JC, Kinjo K, et al. The role of CREB as a proto-oncogene in hematopoiesis and in acute myeloid leukemia. Cancer Cell 2005;7:351-62.

144. Shankar DB, Cheng JC, Sakamoto KM. Role of cyclic AMP response element binding protein in human leukemias. Cancer 2005;104:1819-24.

145. Cheng JC, Esparza S, Sandoval S, Shankar D, Fu C, Sakamoto KM. Potential role of CREB as a prognostic marker in acute myeloid leukemia. Future Oncol 2007;3:475-80.

146. Tan YS, Kim M, Kingsbury TJ, et al. Regulation of RAB5C is important for the growth inhibitory effects of MiR-509 in human precursor-B acute lymphoblastic leukemia. PLoS One 2014;9:e111777.

147. Goswami CP, Nakshatri H. PROGmiR: a tool for identifying prognostic miRNA biomarkers in multiple cancers using publicly available data. J Clin Bioinf 2012;2:23.

148. Alizadeh S, Azizi SG, Soleimani M, et al. The role of microRNAs in myeloproliferative neoplasia. Int J HematolOncol Stem Cell Res 2016;10:172.

149. Kouhkan F, Alizadeh S, Kaviani S, et al. miR-155 down regulation by LNA inhibitor can reduce cell growth and proliferation in PC12 cell line. Avicenna J Med Biotechnol 2011;3:61.

150. Minayi N, Alizadeh S, Dargahi H, et al. The effect of miR-210 Up-regulation on proliferation and survival of mouse bone marrow derived mesenchymal stem cell. Int J Hematol Oncol Stem Cell Res 2014;8(1):15.

151. Ewerth D, Schmidts A, Hein M, et al. Suppression of APC/CCdh1 has subtype specific biological effects in acute myeloid leukemia. Oncotarget 2016;7:48220.

152. Zhang T-j, Zhou J-d, Ma J-c, et al. CDH1 (E-cadherin) expression independently affects clinical outcome in acute myeloid leukemia with normal cytogenetics. Clin Chem LabMed (CCLM) 2017;55:123-31. 